Acta Poetica $36 \cdot 2$

julio-diciembre

$2015(113-126)$

\title{
Ueda Akinari y el gótico japonés
}

\author{
JosÉ RicARdo CHAVES
}

El uso del término 'gótico' en las letras surgió en el siglo XvIII para describir un movimiento que, a contracorriente de la racionalidad recién entronizada, ponía énfasis en el carácter contingente e inexplicable del mundo humano y natural. Coincidentemente, en la misma época se publicó en el archipiélago japonés una colección de narraciones centradas en lo sobrenatural, titulada Ugetsu monogatari, de Ueda Akinari. Este ensayo explora los interesantes paralelismos entre la obra de Akinari y la de escritores como Horace Walpole, Ann Radcliffe y Mathew Lewis, no con el afán de mostrar una relación directa entre el gótico europeo y el "gótico" japonés (algo imposible, dado el aislamiento que marcó el final del periodo feudal en Japón), sino para señalar el carácter transcultural del género, fuera de las estrechas definiciones espaciales y temporales que solemos asignarle.

Palabras ClaVE: Japón, siglo XVIII, Ueda Akinari, gótico.

The term 'Gothic' was first used in literature by the $18^{\text {th }}$ century, referring to a movement that - against the triumphant rationality-emphasized the contingent and unaccountable nature of both the human and the natural world. Coincidentally, a collection of stories with supernatural theme was published in Japan by the same time: Ugetsu Monogatari by Ueda Akinari. This assay explores the interesting parallelisms between Akinari's work and that by authors like Horace Walpole, Ann Radcliffe, and Mathew Lewis. It is not our aim to show a direct relationship between European Gothic and the Japanese "Gothic" (such relationship is not possible, given the isolation prevailing in Japan by the time), but to highlight the transcultural character of the Gothic, not constrained by the narrow spatial and temporal definitions usually given to the genre.

KEYwORDS: Japan, $18^{\text {th }}$ century, Ueda Akinari, gothic. 
Fecha de recepción: 1 de diciembre de 2014

Fecha de aceptación: 2 de marzo de 2015 


\section{JosÉ RicARDo CHAVES}

Universidad Nacional Autónoma de México

Instituto de Investigaciones Filológicas

richavespa@gmail.com

\section{Ueda Akinari y el gótico japonés}

En sentido estricto, las categorías de la historia literaria tienen una aplicación cronológica específica, como cuando pensamos en el barroco y nos remitimos sobre todo al siglo XVIII europeo, o cuando vinculamos lo romántico con el siglo XIX. A veces dichas categorías rebasan sus aplicaciones temporales y espaciales de origen, y adquieren una connotación mayor y transecular, como ocurrió con el concepto 'barroco' en manos de Alejo Carpentier: dejó de ser algo propio de un siglo o de algunos siglos en especial, para tornarse en una suerte de arquetipo estético presente en distintas culturas y tiempos.

Como categoría artística moderna, la de 'gótico' nació ya “desfasada", porque aun cuando alude a lo medieval, a lo propio de los antiguos godos (una cultura bárbara y no-cristiana), surgió apenas en la segunda mitad del siglo XVIII, casi al mismo tiempo en que se discutía el concepto de 'romántico'. Y ambos términos - cómplices entre sí- entraron en conflagración con el paradigma ilustrado que para entonces se iba imponiendo. Así, gótico y romántico aparecen como reacciones a la Ilustración, como intentos de recuperar el lado oscuro de lo humano y de la naturaleza. Presuponen un adversario racionalista, aunque sin asumir el peso de una irracionalidad a secas — como acusan sus enemigos-, sino más bien proponiendo el rescate de potencias que están antes y después 
de la razón: lo inconsciente, las emociones y la imaginación, siendo esta última la facultad humana suprema. Gótico y romántico se alimentaron desde sus inicios de la categoría estética de lo sublime, de origen neoplatónico, reivindicada a mediados del siglo XVIII por Edmund Burke; por entonces se le actualizó en términos de un sentimiento entre estético y místico de lo infinito terrorífico, que anudaba al microcosmos humano con el macrocosmos natural en angustioso abrazo y anunciaba ya al inconsciente freudiano de tipo subjetivo, y sobre todo al inconsciente junguiano de tipo colectivo. No en vano la teorización posterior de los términos 'gótico' y 'romántico', sobre todo en sus derivaciones fantásticas, se hizo con base en el concepto freudiano de umheilich, traducido al español como 'lo siniestro, lo ominoso o lo inquietante', o más recientemente, apoyándose en su heredero posmoderno, como 'lo abyecto', en términos de Julia Kristeva.

A diferencia de lo que pasó con la categoría de 'romántico', que se estabilizó alrededor del siglo XIX, lo gótico prosiguió su desarrollo en el siglo xx, incorporó otros lenguajes, medios y geografías, y se ha mantenido vigente hasta la actualidad, con un carácter popular muy marcado que la alta cultura (incluida la académica) se ha encargado de señalar, primero con ánimo de escarnio y desdén, y últimamente como elogio bajtiniano o sociocrítico. Al principio se pensó en lo gótico como una categoría específica del proceso literario europeo, y en sentido estricto creo que lo es, aunque debe reconocerse que después, sobre todo en el siglo xx, el término se extendió a otras áreas lingüísticas y culturales en un contexto poscolonial y secularizador, con la imposición de la ideología metropolitana, lo que a veces resultaba en un producto gótico exotista. A lo largo del siglo, en el contexto de la creciente globalización occidental se dio una exportación (sobre todo desde la lengua inglesa) de lo gótico, y entonces comenzó a hablarse de un gótico latinoamericano, caribeño o asiático. En estos casos, más que de gótico en sentido estricto se hablaría de 'neogóticos', de 'gótico poscolonial' o algún otro término que acote su posterioridad cronológica y hasta geográfica.

El caso japonés es diferente, pues si tomamos a Ueda Akinari y su obra como punto de partida de una tradición gótica japonesa, lo primero que llama la atención es su simultaneidad con el origen del gótico europeo, ambos surgidos a finales del siglo XVIII (la obra emblemática de 
Ueda es una colección de cuentos fantasmales titulada Ugetsu monogatari, aparecida en 1776). No puede alegarse una influencia occidental a la distancia, pues Japón se encontraba en el aislamiento cultural propiciado por el shogunato, seclusión allanada a cañonazos por el Comodoro Perry en 1854 — cuando se inició la occidentalización del país-. Así pues, el gótico japonés y el europeo nacieron independientemente por la misma fecha, y ninguno es posterior al otro, como ocurre con otros góticos periféricos.

Uno y otro surgieron en contextos muy distintos, con coordenadas culturales e históricas bien diferentes, por lo que la primera reacción es negarse a homologar ambos procesos literarios. ¿Cómo comparar el texto preciosista y casi solitario de Ueda Akinari (sobre un trasfondo de la "literatura del mundo flotante" o ukiyozoshi, algo muy específico de su historia literaria) con el aluvión oscuro en plena Era de las Luces de las obras de Horace Walpole, Ann Radcliffe y Mathew Lewis? Y sin embargo, si superamos esta duda inicial y bien justificada, y vamos más allá de la historia y la cultura disímiles para ingresar al análisis de textos y rasgos, comienzan a surgir algunas correspondencias interesantes que nos hacen pensar en la posibilidad de una comparación justa, de una apuesta analógica más o menos fundamentada.

Atendamos por ejemplo el rasgo de la hibridez genérica del gótico, a la que el propio Horace Walpole aludió en su prefacio a El castillo de Otranto, donde propuso una mezcla de dos tipos de romance, el antiguo y el moderno; uno anclado en la imaginación y en lo improbable, y el otro gobernado por lo probable y conectado con la vida común, con lo que luego llamaríamos realismo (cfr. Hogle: 1). Tenemos entonces la mezcla de géneros y estilos como marca del gótico. Algo similar ocurre en el texto de Ueda, y aquí habría que dar algunos antecedentes. La obra de Ueda surgió en el siglo XVIII, marcado en Japón por una gran vitalidad popular en las ciudades, en donde coexistieron la mano fuerte del samurái y la mano ávida del comerciante burgués, con un emperador débil tras bambalinas. Se produjo un refinamiento urbano de las costumbres y las artes, al que se aludió como el arte de "la vida flotante". Sobre esta expresión apunta Kazuya Sakai, traductor de los cuentos de Akinari al español: 
En la época Genroku, hacia el final del siglo XvII, el término ukiyo, que por su raíz budista originalmente significó "mundo triste" del cambio fugaz y la transitoriedad, adquirió el sentido de "mundo flotante", el mundo del placer y del bienestar material, en otra interpretación de la inestabilidad que domina a este mundo fugaz. Pero la extensión del término acabó por designar lo que era "moda", "estar al día", hasta convertirse en un principio regulador de la conducta y la mentalidad de una gran parte de la burguesía mercantil acaudalada (25).

Así, de la vida flotante se pasó a un "arte flotante" que se expresó en la pintura, en el grabado, y claro, en una narrativa diversa en géneros, fácil, costumbrista, erótica, a veces con cierto descuido literario, destinada al consumo y el entretenimiento, cuyo máximo representante fue Ihara Saikaku. Akinari, por su parte, empieza su actividad literaria afiliado a dicha corriente, y sus primeros textos se inscriben en tal tradición, que ya languidece para cuando él se inicia en ella. Podría decirse que Saikaku abre el ciclo ukiyo y Ueda lo cierra, pues como bien dice Carandell: "entre las obras de ficción de Ihara Saikaku, muerto en 1693, y el libro de madurez de Ueda Akinari, en el último cuarto del siglo XVIII, no se produjo nada realmente perdurable" (14). Después, a mediados de su tercera década de vida, Akinari da un giro al timón literario y se rebela contra el ukiyo, se pone a estudiar chino clásico y literatura antigua japonesa, y desarrolla por única vez un texto de estilo pulido con tema fantástico. El resultado de tal mutación es Ugetsu monogatari, un grupo de relatos sin igual que inscribirá su nombre en la posteridad, será su pasaporte al canon.

En esta colección de historias hay fuentes chinas adaptadas al entorno nipón, lo mismo que menciones de obras representativas de la cultura japonesa. Lo suyo no fue un simple acto mimético, pues por su estilo y tratamientos literarios, sus historias superan con mucho a sus modelos. Hay una admiración por lo clásico, que se mira como absoluto, como meta ideal, por oposición a un presente literario que ya no entusiasma. En palabras de Young:

Akinari himself had come to see the literature of his day as being in a sorry state. As his acquaintance with the masterpieces of the past broadened, it was natural that he felt a yearning for the glories of a bygone 
age and a desire to elevate contemporary literature to a similar plane. In his preface to Ugetsu, Akinari compared his work to Shui hu chuan and The Tale of Gengi. It is doubtful whether he really expected it to prove equally monumental, but it represented his conscious attempt to revive the spirit of the Heian classics, and he had polished it meticulously (52).

En esta obra, Akinari mezcla lo clásico antiguo (en tema y forma) con el ukiyo popular, sometido todo ello a la tensión de un refinamiento lingüístico que no excluye lo histórico ni lo coloquial, en un registro fantástico que cautivará a sus lectores. Al decir de Carandell:

sería incorrecto suponer que el Ugetsu monogatari es un ejemplo y cifra del neoclasicismo dieciochesco. Tiene también la cara del ukiyo, la fuerza popular. Como se ha dicho, el clasicismo de aquel tiempo fue revitalizado por la otra cara, exuberante y frívola, de las nuevas corrientes [...]. En un paso más allá, el propio Ueda Akinari introdujo en esa vena romántica el relato de corte tradicional y de estilo clásicamente perfecto, o, lo que es lo mismo, inquietó la narrativa clásica con el temblor romántico del ukiyo (18).

Es interesante observar cómo los lectores occidentales del giro literario de Ueda, en este caso Carandell, pero también Young (48), terminan refiriéndose a él como "romántico", concepto que se relaciona ambiguamente con lo clásico, en un gesto de hibridación textual, proyectando así en el mundo japonés sus categorías críticas europeas. ¿No nos recuerda esta operación de escritura llevada a cabo por Akinari la propuesta de Walpole cuando hablaba de mezclar lo antiguo y lo moderno? Es así como el rasgo de hibridez en cuanto al género y estilo - pero también en cuanto a la alta y baja cultura - con que se ha caracterizado al gótico europeo calza también para el caso de Ueda Akinari.

Kazuya Sakai ha traducido al español el título Ugetsu monogatari como "Cuentos de luna y de lluvia" (1969), y Manuel Serrat como "La luna de las lluvias" (2009); a diferencia del primer traductor, Serrat excluye del título el aspecto narrativo implícito en el término "monogatari", una categoría de relato sin equivalente exacto en la literatura occidental, pues combina novela, narración histórica, cuento de hadas, poesía, folletín, costumbres y amores, una marca más del mestizaje de 
género. Piénsese al respecto en el famoso libro Genji monogatari, un clásico de la literatura japonesa de principios del siglo XI, escrito por la dama de la corte Murasaki Shikibu, alabado por autores como Borges, Paz y Yourcenar y que se ha traducido al español como "relato", "romance" o "historia" de Genji, el personaje masculino de eso que a un lector contemporáneo le parece una novela. Volviendo a Akinari, su título alude al momento cuando el autor terminó de escribir sus historias, una noche en que la luna brillaba turbiamente entre las nubes después de la lluvia, por lo que también podría traducirse, según Young, como "cuentos de luz de luna y de lluvia" o bien "cuentos de la luna nublada". En todo caso, en él se privilegian el agua, la luz lunar, la penumbra; se trata de relatos húmedos, de claroscuros, que vehiculan en sus signos terribles toda suerte de demonios y de espectros.

Resulta llamativo que Akinari, quien provenía del ukiyo realista, dé este giro de registro hacia lo fantástico de manera excepcional, pues es el único título en su obra con estas características no-miméticas, y sin embargo ha eclipsado a todo el resto, consistente en seis obras más. Como afirma Young: "Ugetsu was to be Akinari's only venture into the literature of the supernatural, yet it has proved superior to all of its predecessors and followers in the genre in Japan. Like no other work, it combines a vivid ghostly atmosphere with a poetic style that is a delight to read" (53). Poco antes, Young había dicho que "Akinari produced a work of eerie beauty that represents the highest artistic level reached by the supernatural tale in Japan" (50).

De los lectores de Akinari que se han preguntado sobre la importancia de las creencias del autor en lo sobrenatural para elaborar sus relatos, Young tiende a disminuirla al afirmar que no fueron incompatibles con lo que llama "una visión racional de la vida", lo que se ve más en el resto de su obra, mientras que Kazuya Sakai, si bien acepta la fuerza de tales creencias en el autor, considera arriesgado "considerar este aspecto de su inclinación como motivación directa y principal en la creación de Ugetsu" (20). Y así debe de ser, puesto que como señalamos, lo fantástico es excepcional en su trabajo literario pero no así en su vida personal, pues según la leyenda fue salvado de la muerte por el dios-zorro Inari. Parece que el afligido padre de Akinari acudió al templo de dicho dios para pedir por la salud de éste, quien agonizaba. 
El hombre se quedó dormido en medio del rezo y la meditación y tuvo una visión en la que se le aparecía el dios para predecir la curación del niño, proclamando que viviría hasta los 67 años (de hecho, murió a los 75). El autor mantuvo su devoción hacia ese dios (inscrito en su propio nombre) por el resto de sus días, y hasta le ofrendó poemas.

En los cuentos de Akinari, los fantasmas que pueblan los textos chinos y del viejo Japón dejan de ser planos, unidireccionales, dedicados simplemente a aterrorizar como en la leyenda oral, y adquieren psicología y alta expresión estética sin dejar de asustar, o mejor, de asombrar. En este sentido me resultan muy modernos e inquietantes, y por eso causaron revuelo entre sus coetáneos; además, la modernidad que bien pronto encauzaría al país supo también reconocer en ellos un tesoro literario, vigente hasta la actualidad. Akinari escribió en una época en que - a su juicio - la sociedad decaía en relación con un pasado ideal y clásico. Hay en sus cuentos un componente ético importante, porque sin llegar a la moraleja se encuentra de pronto la alabanza de alguna virtud que falta en el mundo presente. Es el caso de la fidelidad y la hermandad en uno de los primeros cuentos del Ugetsu, "Cita en el día del crisantemo", que para juicio de muchos es la mejor historia del conjunto.

El escritor contemporáneo Haruki Murakami la resumió así en su novela Kafka en la orilla, por boca de uno de sus personajes:

Dos guerreros se hacen amigos y juran ser hermanos de por vida. Entre samuráis, este juramento es muy importante. Hacer esta promesa equivalía a poner la vida en manos del otro, a entregarla gustosamente por el otro de ser necesario. Eso significaba. Los dos viven en regiones muy alejadas y sirven a dos señores diferentes. "Cuando el crisantemo esté en flor, iré a visitarte", le anuncia uno al otro. "Te espero", responde el otro. Sin embargo, el samurái que tenía que ir a visitar a su amigo se ve envuelto en problemas en su señorío y es arrestado. No puede salir. Tampoco le está permitido escribir una carta. Pronto acaba el verano, avanza el otoño y llega la estación en que florecen los crisantemos. El samurái no puede cumplir la promesa que le ha hecho al amigo. Para un samurái, una promesa tiene una importancia capital. La fidelidad tiene más valor que la propia vida. El samurái se suicida abriéndose el vientre y su espíritu recorre una larga distancia para reunirse con su amigo. Ambos, 
ante las flores del crisantemo, hablan hasta la saciedad y luego el espíritu desaparece de la faz de la Tierra. Es una historia preciosa (285).

Sí, es una historia preciosa pero aparece de forma un poco distinta en el texto de Ueda, pues para empezar sólo uno de los dos amigos es samurái, mientras que el otro es un letrado, y esto no era insignificante en la sociedad japonesa. El guerrero enferma cuando está de paso por la tierra del artista; éste lo cuida asiduamente hasta que aquél recupera la salud y se marcha a cumplir sus obligaciones militares, tras hacer la promesa del reencuentro. Este proceso está descrito con una carga no sólo fraternal, sino también erótica, aunque de manera más bien velada. Esta sutil y creciente carga homoerótica es la razón por la que Murakami recuerda el texto de Akinari como si fuera un cuento de amor entre samuráis, haciendo una conexión quizá involuntaria con los relatos del maestro del ukiyo ya mencionado, Ihara Saikaku, específicamente con su conjunto de historias de amor entre samuráis titulada El gran espejo del amor viril, de 1687, y que tanto Akinari como Murakami conocieron. ${ }^{1}$ Este rasgo homoerótico añade una carga transgresora al cuento, en donde el deseo termina superando a la muerte, y ésta es una característica que amarra a Ueda con lo gótico, en donde también la sexualidad suele tener esta dirección a contracorriente.

En este cuento el homoerotismo se sublima por medio de la fraternidad y la lealtad ante todo, pero no siempre es así: también puede salirse de control, como ocurre explícitamente en otra historia del conjunto llamada "El capuchón azul", en donde un monje virtuoso cae en desgracia por el amor a un mancebo. El problema, en términos budistas, no es el objeto de su deseo sino el simple acto de desear, y sobre todo, como en este caso, con un apego tal que lleva al protagonista a transformarse en un monstruo que espanta al pueblo tras devorar el cadáver del joven, muerto por una extraña enfermedad. El monje caído se salvará por la

${ }^{1}$ Resulta llamativo que el célebre director de cine Nagisa Oshima (1932-2013) mencione en su película Gohatto (1999), que trata justamente de historias de amor entre samuráis, el cuento señalado de Ueda Akinari, y que lo haga con cierto detalle por medio de uno de sus personajes; por otra parte, sí es consciente de que en el texto se trata del amor entre un samurái y un letrado y no de dos samuráis, como glosa erróneamente Murakami. 
intervención de otro monje, un viajero que llega al lugar e interviene exitosamente para su recuperación búdica, la que sin embargo supondrá también su desaparición física.

La diferencia entre la narración de Akinari con las historias de amores prohibidos entre monjes y mancebos que cuenta su antecesor Saikaku es abismal, pues aquél no se limita a hacer una crónica del deseo flotante, con sorna o picardía, sino que la pasión desbordada literalmente convierte en monstruo al personaje, lo vuelve sujeto de la imaginación gótica y termina disolviéndolo en polvo y aire. Debe tenerse en cuenta que la libertad con que Akinari aborda lo homoerótico se debe a la distinta concepción de la homosexualidad masculina en Japón antes de su occidentalización, con una tradición más liberal al respecto, sin la carga de culpa, pecado y perdición por nosotros conocida. Como acabamos de mencionar, Saikaku había escrito sus historias de amor entre samuráis un siglo antes de Akinari, y autores más recientes que también abordaron en sus obras el tema homosexual, como Yukio Mishima en el siglo pasado, reconocen dicha diferencia cultural entre Japón y Occidente en la valoración de lo homosexual, tal como lo hace Mishima en su novela El color prohibido, en la que directamente se refiere a Saikaku y a Akinari como sus antecesores japoneses en la narración de historias homoeróticas.

Otra correspondencia en nuestra apuesta analógica intercultural entre el gótico europeo y el japonés se refiere a la importancia narrativa del 'lugar encantado', ese sitio antiguo o en ruinas, escenario de algo ido y desconocido, poseedor de un secreto cuya develación es parte del atractivo de la narración. Es el locus propicio para toda suerte de fantasmas, representantes justamente de ese tiempo desaparecido y velado, pero no por ello disuelto sino apenas latente, flotando en el aire como una nube amenazadora que podría volverse tormenta. Se establece una relación estrecha entre el espacio, el fantasma y el secreto. En palabras de Hogle:

Within this space, or a combination of such spaces, are hidden some secrets from the past (sometimes the recent past) that haunt the characters, psychologically, physically, or otherwise at the main time of the story. These hauntings can take many forms, but they frequently assume the 
features of ghosts, specters, or monsters (mixing features from different realms of being, often life and death) that rise from within the antiquated space, or sometimes invade it from alien realms, to manifest unresolved crimes or conflicts that can no longer be successfully buried from view (2).

En el relato "La cabaña entre las cañas esparcidas" nos encontramos de nuevo con el tema del reencuentro de los amantes separados por circunstancias adversas, como vimos en el ya comentado "Cita en el día del crisantemo": uno en clave heterosexual, centrado en la mujer fiel y su esposo comerciante que retorna, y el otro en clave homosexual entre el samurái y el letrado, siendo este último quien asume la función de esperar al otro. La fidelidad es el valor ético y erótico que sostiene ambas historias. Mientras en uno quien espera en la casa abandonada es la muerta al vivo, en el otro es el vivo quien aguarda en su casa al muerto. En ambos casos hay un reencuentro breve, lo que dure la luna tras la lluvia, del vivo con el muerto (o la muerta), ignorando el primero que la efímera compañía es la de un fantasma (también el lector lo ignora, y el descubrirlo es parte del efecto narrativo).

En el cuento "La impura pasión de una serpiente" la casa fantasmal es asimismo un espacio importante, el lugar derruido que por magia erótica se reconstruye y sirve de ámbito al encuentro entre un hombre y una mujer que se obsesionará con él y que lo perseguirá a lo largo de la historia; es una mujer que reúne atributos humanos y animales, específicamente de serpiente. En vez del espacio maravilloso que el hombre experimenta, lo que otros personajes ven se describe de manera muy distinta:

El interior se veía más derruido que el exterior. Los guardias se internaron más y más. Los jardines eran muy amplios. El lago artificial del jardín y las plantas acuáticas estaban totalmente secos; en medio de un zarzal aplastado se erguía, tenebroso y trágico, un pino abatido por el viento. Cuando abrieron la puerta de la sala de recepción los acogió un soplo de aire con olor acre, fantasmal, que los hizo estremecer; la partida retrocedió, sobrecogida de temor (Ueda 1969: 138).

Con este cuento se entra de lleno en el motivo de los personajes femeninos nefastos que hablan de mutaciones debidas a pasiones impuras 
y desmedidas, a veces tomados de la mitología tradicional. En este caso tenemos a la mujer-serpiente que persigue al viril objeto de sus deseos, pero en el cuento "El caldero de Kibitsu" encontramos una situación distinta, no lo femenino que desde el principio es maligno, sino la mujer fiel y tradicional, epítome de las virtudes femeninas (igual que la muerta que esperaba al marido ausente en "La cabaña entre las cañas esparcidas"), pero que debido a las infidelidades continuas del consorte se va transformando en un monstruo celoso que destruirá a sus enemigos. Al decir de Kazuya Sakai, este cuento

está considerado por los críticos especializados como el cuento que dentro de Ugetsu y aun de toda la literatura japonesa, representa un logro en horror y suspenso [...] La impresionante escena de la aparición (del fantasma), seguida de la horrible venganza que descarga sobre su marido, resumen su invención magistral del horror y del suspenso (46-47).

Mientras las mujeres de "El caldero de Kibitsu" y "La impura pasión de una serpiente" fácilmente entran en el arquetipo de féminas fatales, la de "La cabaña entre las cañas esparcidas" es más bien su opuesto y encarna la virtud confuciana, subordinada al padre, al esposo, al hermano o al hijo.

Desde una cierta ideología misógina, si bien la mujer es más proclive que el hombre para caer posesa de pasiones impuras, que incluso pueden pasar de una vida a otra (dado el contexto budista de renacimiento y karma), el hombre que se descuida es también susceptible a ello, tal como vimos con el monje de "El capuchón azul", quien por la pasión desmedida hacia un mancebo perdió su virtud y se transformó también en un monstruo depredador, hasta que intervino un monje firmemente virtuoso. En todos estos casos, el mucho desear, el anhelar en exceso monstruifica, samsariza, sumerge a hombres y mujeres en la rueda de la vida y de la muerte, los vuelve animales y demonios, metamorfosis que sólo acaban cuando la virtud los libera de su tremendo sufrimiento. Como puede apreciarse, hay un indudable sabor budista que permea estas historias.

Sirvan estos esbozos críticos a los cuentos de Akinari para afirmar su pertenencia al género gótico, a pesar de sus especificidades cultura- 
les e históricas. Éstos permiten conceptualizar dicho género como una categoría transcultural, como un puente de signos siniestros, siquiera a modo de hipótesis a partir del caso de este excelente autor japonés, que no en balde ha fascinado a propios y extraños. Aquí cabe mencionar, en las letras mexicanas, a Carlos Fuentes, quien se refiere a los cuentos de Akinari como una de sus influencias mientras escribía Aura; y no sólo al texto escrito, sino sobre todo a la versión cinematográfica que hizo Kenji Mizoguchi en 1953 y que ganó el León de Oro en el festival de cine de Venecia.

\section{BIBLIOGRAFÍA}

CARANDell, José María. "Presentación" a La luna de las lluvias (Ugetsu monogatari) de Akinari Ueda. Trad. Manuel Serrat Crespo. Barcelona: José J. de Olañeta Editor, 2009: 14, 18 y 48.

Hogle, Jerrold E. (ed.) "Introduction: the Gothic in the Western Culture", en The Cambridge Companion to Gothic Fiction. Cambridge: Cambridge University Press, 2002: 1-20.

Lovelace, AdA. "Ghostly and Monstruous Manifestations of Women: Edo to Contemporary", en The Irish Journal of Gothic and Horror Studies. Issue 5 (December 2008). Artículo disponible en <irishgothichorrorjournal. homestead.com/jwomen.html $>$ [fecha de consulta: 19 de enero de 2015].

Murakami, Haruki. Kafka en la orilla. México: Tusquets, 2002.

SAKaI, KazUYA. "Introducción" a Cuentos de lluvia y de luna de Akinari Ueda. Introd., ed. y trad. Kazuya Sakai. México: Era, 1969: 20-25, 46-47.

Ueda, Akinari. Cuentos de lluvia y de luna. Introd., ed. y trad. Kazuya Sakai. México: Era, 1969.

Ueda, AKinari. La luna de las lluvias (Ugetsu monogatari). Presentación de José María Carandell. Trad. Manuel Serrat Crespo. Barcelona: José J. de Olañeta Editor, 2009.

Ueda, Akinari. Cuentos de lluvia de primavera. Prólogo de Carlos Rubio. Trad. Yoshifumi Kawasaki. Gijón: Satori, 2013.

Young, BlaKe Morgan. Ueda Akinari. Vancouver: University of British Columbia Press, 1982. 